\title{
Ainda Sobre as Diversas Eficácias e Efeitos da Sentença
}

\author{
Fernando Sá \\ Advogado em Porto Alegre
}

Sumário: 1. Introdução. Liebman e Carnelutti. 2. Vagueza dos termos, eficácia e eficácia da sentença. 3. A curiosidade despertada a partir das idéia de Pontes de Miranda. 4. As idéias de Ângelo Falzea. 4.1. Prolegômenos. 4.2. Conceituação de eficácia. 5. Nosso entendimento. 6. O problema das sentenças declaratórias, ainda sob Ângelo Falzea. 7. Conclusão.

\section{Introdução. Liebman e Carnelutti}

A despeito das muitas reflexões realizadas sobre as significaçōes da linguagem natural e dos expressivos avanços alcançados neste sentido pela Filosofia da Linguagem Ordinária ${ }^{1}$, o real significado do termo eficácia, e o da expressão corolária, eficácia da sentença, teima em permanecer em brumas.

Aparentemente, a histórica batalha doutrinária travada entre Carnelutti e o então jovem professor Liebman, sobre o tema e a categoria também correlatada da coisa julgada só fez adensar a névoa, tornando ainda menos perceptível a distinção entre os termos eficácia e efeitos da sentença.

De fato, como por todos sabido, de um lado Liebman colocou a eficácia natural da sentença como a aptidão de produzir efeitos, e atribuiu à coisa julgada a especial qualidade dos efeitos que toda a sentença tem.

${ }^{1}$ Luis Alberto Warat, in O Direito E Sua Linguagem, Porto Alegre, Sergio Antonio Fabris, 1995, 2a ed. pp. 65 e ss. esp. 76] 
Carnelutti, a seu turno, quer a eficácia como o efeito criativo do direito concreto e a imutabilidade da coisa julgada como a estabilidade da sentença não mais sujeita a recursos ${ }^{2}$.

2. A vagueza dos termos, eficácia e eficácia da sentença.

A vagueza natural do vocábulo, eficácia, mais acentuada fica, quando é o próprio Código de Processo Civil [art. 467] quem denomina de coisa julgada material a eficácia que torna imutável e indiscutível a sentença, em nada contribuindo, pois, ao aclaramento de seu significado.

A imprecisão do termo, e até mesmo da exata representação que se faz da locução eficácia da sentença, torna-se ainda maior quando se nota, através da pena de jurista de tomo, em sua conceituação de tutela jurisdicional, a idéia de que seja esta a produção de efeitos exteriores ao processo. ${ }^{3}$

Embora prossigamos considerando que a vagueza denotativa do termo eficácia encontre limites mais precisos no uso pragmático da linguagem comum, vale dizer, no contexto verbal em que esteja inserida, nenhum mérito maior se almeja com esta breve digressão, senão o de externar as conclusōes a que se chegou após havermos lido, e dele extraído o que nos pareceu a idéia-matriz, o magnífico ensaio da lavra de Angelo Falzea, sobre a Efficacia Giuridica, na Enciclopedia del Diritto [Varese, Giuffrè Editore, 1965, vol. XIV].

\section{A curiosidade despertada a partir das idéias de Pontes de Miranda}

Em verdade, a curiosidade a respeito do tema foi despertada a partir das primeiras linhas do vol. 4, do Tratado de Direito Privado, quando Pontes de Miranda declara que a eficácia são os efeitos que se irradiam do ato jurídico que se deseja eficiente. ${ }^{4}$, mesmo porque e em tom de blague, em nenhuma ocasiáo nos deparamos com expressão contrária, isto é, a de que efeitos possam irradiar eficácias.

${ }^{2}$ Cândido Rangel Dinamarco, in Fundamentos do Processo Civil, São Paulo, Malheiros, 2000, 3ª ed. vol. I, pp. 293-296.

${ }^{3}$ A idéia é retirada das lições do autor Cândido Rangel Dinamarco em sua obra já aludida, vol. II. pp. 811 e ss. esp. 812, ao ministrar que "A tutela é o resultado do processo em que essa função se exerce. Ela não reside na sentença em si mesma como ato processual, mas nos efeitos que ela projeta para fora do processo e sobre as relaçōes entre as essoas". [grifo do a.]

${ }^{4}$ Pontes de Miranda, in Tratado de Direito Privado, Rio de Janeiro, Borsoi, 1970, $3^{\mathrm{a}}$ ed., vol. 4, § 356 ,

p. 3] Nas palavras do mestre [sic] "Para que o ato jurídico possa valer, é preciso que o mundo

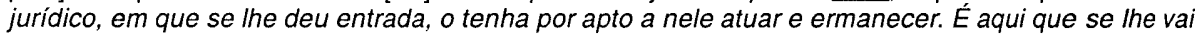
exigir a eficiência, quer dizer - o não ser deficiente; porque aqui é que os seus efeitos se terão de irradiar (eficácia)". [grifos do a.] 
Sem embargo, a toda evidência, é uníssona a consciência da comunidade jurídica sobre a real conotação, e das possíveis denotações, a respeito da locução efeito jurídico, algo que, no entanto, longe está de se poder afirmar acerca de eficácia, que cambia, polissêmica, segundo a liberdade estética e o domínio literário que possua autor privilegiado sobre as regras do uso desses vocábulos e locuções.

Talvez seja por isso também que, a propósito, a primeira imagem que nos colhe o espirito é a de um disparo de canhão, querendo com isso representar que o petardo, após sua trajetória, ao atingir o alvo, explodindo, é eficiente, donde, pois, a eficácia, e daí seus efeitos. Caso não explodir, é deficiente, portanto ineficaz, deixando de produzir os esperados efeitos.

Grosso modo, a imagem valeria para quatro das cinco eficácias enunciadas pelo mestre Pontes de Miranda [constitutiva, condenatória, executiva e mandamental] que são hoje inequivocamente admitidas como naturais à sentença, exceto a quinta, a declaratória, também natural, pois apresenta peculiaridades próprias e uma aparente contradição em termos anotada e, a nosso juízo, logo brilhantemente desfeita, pelo citado jusfilósofo italiano Angelo Falzea.

\section{As idéias de Ângelo Falzea.}

4.1. Prolegômenos

À partida colocamos, seguindo doravante os passos do autor, que as várias doutrinas acerca de a teoria da eficácia jurídica - que acreditamos válida também para a apreensão extensiva do significado da locução, eficácia da sentença -, encontram-se na dogmática do Direito, insetilmente ligadas à teoria dos efeitos jurídicos, "che va derivata dalla nozione di norma e contrapposta alla nozione di fatto"s.

Donde se depreende que a tarefa de precisar a significação do termo não se apresenta sem empecilhos sérios a transpor, fazendo-se necessário a utilização de definições ou designações auxiliares ou aclaratórias.

Assim recorre o autor, no estudo sobre a eficácia jurídica, a par a norma e o fato, a outras categorias jurídicas, como a situação jurídica, sobremaneira à figura do dever, que particularmente nos interessa; ao tempo do efeito ${ }^{6}$ e à teoria da transformaçáo jurídica, isto é, a transformação ocorrida pelo efeito no tempo.

\footnotetext{
${ }^{5}$ Angelo Falzea, ob. cit., $\S 25$, p. 464.

6 Idem, ibidem. O autor ainda faz notar que, aqui, "non è tanto il tempo della sua realizzazione effectiva quanto il tempo logicamente e cronologicamente anteriore della sua posizione prospettica".
} 
As idéias ora expostas são as do autor. Advertimos haver feito uso extenso de suas próprias palavras, visto não termos alcançado sucesso em nos despegar por inteiro do texto original, como seria academicamente desejável, tampouco de encontrar outras melhores que viessem a expressar com a mesma adequação e clareza seu pensamento.

Nosso intento, como acentuado, foi tão-somente o de inferir da leitura a depreensão do que Falzea tem por eficácia e daí então, como subproduto, vir a dessumir o sentido da expressão, eficácia da sentença, e os efeitos dela irradiados.

Para Falzea a base da teoria dogmática sobre a eficácia recai na noção de norma jurídica, cujo ponto de partida de sua construção doutrinária reside no valor, ou, per usare un termine più diffuso tra i giuristi, o interesse.

Para cada norma jurídica, deixa sinalado, existe um valor também jurídico correspondente em que restará especificado o interesse da comunidade jurídica. Na grande maioria dos casos, um valor jurídico determinado não é admitido incondicionalmente em um sistema de valores, senão sob a condição de que anteriormente se haja produzido um fato ou um complexo de fatos.

Tirante certas peculiaridades, a norma se configura como uma proposição hipotética ou condicional, e, em face disso, surgem três componentes lógicos: a proposição condicionante, a proposição condicionada e a relação de causalidade, sendo as duas primeiras proposições temporais. ${ }^{8}$

À teoria da norma conecta-se tradicionalmente a definição de efeito jurídico, que, para existir, pressupõe uma relação de condicionalidade, onde o condicionante é um antecedente de fato e o condicionado um valor jurídico. ${ }^{9} \mathrm{O}$ efeito da norma não é nem o simples valor, nem o simples fato, e sim o valor atribuído ao fato. ${ }^{10}$

O que importa salientar é que nos mais diversos efeitos, o atributo de valor é genérico e sempre o mesmo, no que reside o interesse fundamental da comunidade jurídica, "o ponto de confluência unitário de todos os valores do sistema." 11

\footnotetext{
${ }^{7}$ Idem, ob. cit. § 31, p. 470.

${ }^{8}$ Idem ibidem, p. 471

${ }^{9}$ Idem, ibidem, $\S 32$, p. 472.

${ }^{10}$ Idem, ibidem, $\S 33$, p. 473.

1 Idem, ibidem, p. 473.
} 
É a partir daqui, ao dar início ao parágrafo 34 de seu ensaio, quando analisará o confronto entre fato jurídico e a componente de fato do efeito jurídico ${ }^{12}$, que Angelo Falzea perpassa às agudas observaçóes que nos auxiliaram a afastar a imprecisão do termo eficácia.

Segundo ele, fato jurídico e componente de fato do efeito jurídico têm a mesma estrutura lógica fundamental; cada uma referida a seu próprio tempo, dando lugar, portanto, a uma situação temporal.

Prossegue notando que entre essas duas situações temporais subsiste a relação axiológica, ou seja, a situação que faz entrar o fato jurídico na dimensáo do tempo, caso o evento se verifique, no que se constitui então, para a comunidade jurídica, uma exigência ou um problema prático.

Daí a procura prosseguida pela comunidade jurídica de uma satisfação para a exigência e de uma solução para o problema. Somente encontrar-se-á satisfeita a exigência e o problema prático resolvido, face à outra situação, ou seja, àquela que faz entrar a componente de fato do efeito jurídico, no tempo. ${ }^{13}$

Chegados a este ponto e estando de posse das definições ou designações auxiliares feitas e estabelecidas, poderemos então mais facilmente depreender, já agora do exame da categoria da situação jurídica, na seção III do ensaio, a conceituação de eficácia, a nosso sentir deixada implícita por Falzea, quando discorre sobre a figura do dever ${ }^{14}$.

\subsection{Conceituação de eficácia.}

Deveras, foi somente ao lermos essa descrição que nos apercebemos, a final, da fina, sutil e permanentemente abstrata significação jurídica, em contraponto à perene objetividade do termo efeito, que a palavra da linguagem natural eficácia tem para a Teoria Geral do Direito.

O texto a seguir, em homenagem à importância que lhe emprestamos, e, sobretudo, à clareza das idéias do eminente jurista italiano, é uma tradução livre das passagens mais expressivas de sua exposição. Não se encontram os parágrafos, entre

\footnotetext{
12 Idem, ibidem, $\S 34$, p. 473. Falzea indica para uma representaçāo lógico-formal do efeito jurídico "il valore generico deve figurare logicamente come una costante, i fatti specifici non potranno essere espressi logicamente se non come variabili [...] è opportuno adesso mettere a confornto col fato giuridico non più l'intero effeto giuridico, ma la sola componente di fatto dell'effeto, distinta e idealmente isolata dalla componente di valore" [grifamos].

${ }^{13}$ Idem, ibidem, p. 473.

14 Idem, ibidem, § 37, p. 477.
} 
aspas, como prescreve as boas regras da comunicação da prosa moderna, por mero detalhe, ou por capricho.

Isto posto, acentua o ilustre ensaísta que entre as duas idéias, de situação jurídica e de efeito jurídico, existe um estreito nexo; basta que o efeito jurídico se concentre em certos sujeitos que cumpram, ou que acolham os atos de outros sujeitos, para que se produza uma situação jurídica.

Em todo o efeito jurídico vem considerada e avaliada uma situação do mundo em função de algum interesse fundamental que é o da comunidade jurídica.

O pressuposto da avaliação é que, num determinado tempo, cumpra-se uma fattispecie juridicamente definida. Sob essa condição específica cuida-se avaliar, em face do sistema total dos interesses tutelados pelo direito, o valor que a situação assume no tempo subseqüente, isto é, no futuro.

Um especial valor é assumido pela situação, com determinado suporte fático, que se demonstra, assim, necessária para a tutela do sistema dos interesses jurídicos.

A situação realmente assume um valor necessário, no momento em que a ordem jurídica já se encontra a ponto de estabelecer, no tempo dado em que a fattispecie ocorre, se e somente se, no tempo subseqüente, o interesse da comunidade jurídica está satisfeito por ter a situação ocorrido.

Ora, diz o autor, é demonstrável que em toda a norma jurídica o efeito jurídico contém in nuce uma avaliação de necessidade. É óbvio que em face de um efeito determinado nem todas as situaçóes serão sindicadas como necessárias. Mas aí pelo menos uma haverá, cuja necessidade está colocada na posição do próprio efeito, e esta será a situação em que, ao se verificar, satisfaz, e ao não se verificar deixa insatisfeito aquele particular interesse da comunidade jurídica definido pelo efeito.

Por exemplo, em um contrato de mútuo, a situação temporal na qual se cumpre o pagamento da soma mutuada, no tempo estabelecido, é a situação, que, em se verificando, satisfaz e, ao revés, permanece insatisfeito o interesse da comunidade jurídica, precisamente porque esta situação é sindicada como necessária pelo direito.

Bem entendido, cura-se de uma necessidade axiológica e não de uma necessidade física; duma necessidade que exsurge do ordenamento jurídico e não do mundo físico. Vê-se, pois, que em toda a norma existe uma necessidade axiológica imediatamente ligada ao efeito da norma. Toda a norma particular define, no próprio efeito, um particular interesse da comunidade jurídica, donde existir uma situação necessária para a satisfação deste interesse. 


\section{Nosso entendimento.}

Eis pois aqui o que consideramos como sendo a conceituação do termo eficácia. Esse fenômeno jurídico, através do qual o Direito se realiza, é aquele instante da situação jurídica, quando um especial interesse, tido como necessário pela comunidade jurídica, passa à concreção de determinada fattispecie posta na hipótese legal para que se cumpra o efeito jurídico nela valorado e pretendido.

Trata-se de uma necessidade axiológica, e não de uma necessidade física, com vimos. Vale dizer, toda norma jurídica define, no próprio efeito, o interesse pretendido existir pela comunidade jurídica, e, por conseguinte, uma situaçāo de possibilidade necessária que satisfaça este interesse e efetivamente garanta sua tutela.

É, enfim, aquele momento fugaz, abstrato, imaterial, decorrente de um ato ${ }^{15}$, mas que antecede o efeito, ou os efeitos, estes sim objetivos, materiais.

Foi nesse sentido que, e por isso mesmo, em trabalho anterior consideramos que a sentença comportava uma só eficácia e, em seu conteúdo, vários efeitos, exatamente como na imagem metafórica do disparo de um canhão, trazida ao darmos início à digressão.

\section{O problema as sentenças declaratórias, ainda segundo Ângelo Falzea.}

Valeria, no entanto, a conceituação a que chegamos também para as sentenças declaratórias? Dificilmente, mas é ainda a Angelo Falzea a quem nos socorremos para iluminar o caminho na tentativa de elucidar este quê de mistério a envolver algumas situações jurídicas e a provocar dores de cabeça em eminentes processualistas. Para tanto precisaremos volver algumas páginas e depois avançar sobre outras neste fantástico saggio.

Quando analisa o efeito, no confronto entre fato e a componente de fato do efeito jurídico, a que já nos referimos, Falzea observa que ambos temporalmente se distinguem, muito embora o conteúdo e a estrutura tendam à identidade.

Essa distinção torna-se mais patente quando o fenômeno cuida de normas de transformação [constituição, modificação e extinção], em que a situação originária na qual o fato jurídico se produz seja mais ou menos alterada. ${ }^{16}$

\footnotetext{
${ }^{15} \mathrm{Idem}$, ibidem, $\S 34$, p. 474, o autor, ao apontar as diferenças entre fato jurídico e componente de fato do efeito jurídico, não deixa ao mesmo tempo de observar que o fato jurídico pode ser, ou não, um ato. Segundo ele "Si tratta di eventi che, almeno nella loro normalità, non dispendono dalla volontà umana. Invece, la componente di fatto dell'efetto giuridico è sempre e necessariamente un atto."

16 Idem, ibidem, § 34, p. 474.
} 
Lembra então que para a doutrina tradicional a eficácia jurídica pode apenas se referir às três formas conhecidas de transformação, embora já de algum tempo venha sendo debatida a necessidade de se encontrar uma explicação adequada para um tipo de eficácia distinta daquelas.

O debate se põe relativamente à capacidade, ou não, de certos fatos, que a despeito de serem incontestavelmente jurídicos, poderem produzir situações jurídicas novas, como, v.g. a sentença.

Como a função institucional duma decisão judicial muitas vezes é tão-somente a de declarar que a situação jurídica nova deve ser mantida e conservada tal qual a pré-existente, não se pode, a despeito disso negar que esse fato não dispõe do mesmo tipo de eficácia semelhante àquela atribuído ao fato constitutivo. Residiria aí, então, o paradoxo da eficácia da sentença declarativa ${ }^{17}$.

Afinal, cabe perquirir, como poderia "um fato que não produz inovação no estado jurídico pré-existente e cujo fim específico é o de manter inalterada a situação jurídica sobre a qual incide, vir a distinguir-se de um fato irrelevante, já que por definição são juridicamente irrelevantes os fatos que não trazem novidades ao mundo do direito?"18

De pronto responde ser o paradoxo meramente aparente. O que existe de diverso entre os fatos declarativos ou conservativos daqueles ditos transformativos é o tipo de novidade introduzida por qualquer um deles no mundo jurídico.

A explicação inicia-se pela observação de que estes últimos pertencem à categoria das transformações externas, alterando-se, "de forma mais ou menos substancial a situação jurídica considerada". ${ }^{19}$

Elucida o problema de como poderia ocorrer uma transformação em determinada situação jurídica sem alterar-lhe o conteúdo, utilizando-se de uma argumentação que procuraremos ora resumir.

Tendo em linha de conta que toda a situação jurídica é essencialmente temporal, isto é, resolve-se no tempo, por via de conseqüência, pode ocorrer que "a transformação chegue a um evento novo, incompatível com o esquema da situação jurídica pré-existente, pela alteração de elementos essenciais, objetivos e subjetivos. ${ }^{20 "}$

Assinala contudo, e aqui o ponto, que pode dar-se também que a transformação ocorrida no tempo seja totalmente compatível e coerente com a anterior, não havendo

\footnotetext{
17 Idem, ibidem, § 50, p. 492-493.

18 Idem, ibidem, p. 494

${ }^{19}$ Idem, ibidem, p. 494

${ }^{20}$ Idem, ibidem, p. 494
} 
sido modificado o conteúdo essencial nem estrutural da situação jurídica considerada, que permanece inquestionavelmente a mesma.

Desta sorte, realmente a imagem inicial invocada fica a dever quanto à eficácia declarativa, pois exigiria um esforço intelectual inútil, em nada contribuindo para o entendimento procurado. Afinal, sobre o que de positivo haveria de declaratório em uma explosão, senão a acaciana e ridícula declaração de haver produzido um estrondo! Por outro lado, nosso objetivo sempre foi, confessadamente, o de intentar reduzir a vagueza do termo, extraindo deste fantástico ensaio de Angelo Falzea as preciosidades que ele tão prodigamente esbanjou.

\section{Conclusão.}

Ao fim e ao cabo, gostaríamos de recordar, com Luis Recaséns Siches, que naquilo que nos acostumamos denominar de "aplicação do Direito", o que lhe sobrevem é tão importante e necessário que somente poderemos compreender o que realmente ele seja, senão através dos efeitos que produza sua aplicaçáo sobre as realidades humanas existentes. ${ }^{21}$

Com Recaséns, "una norma jurídica es lo que ella hace. Si una norma jurídica no opera real y efectivamente, no puede ser llamada Derecho, pues se reduce a ser un mero pedazo de papel o unas voces en el desierto." 22 [grifamos].

Assim também a sentença, que dá curso ao ordenamento positivado pelo legislador no momento da interpretação e aplicação da norma, seria um mero flatus voces, caso as valorações criadas pelo órgão jurisdicional, sobre o particular, deixassem de carregar em si a eficácia pretendida pelo Direito, produzindo os efeitos aguardados pela comunidade que o observa e o quer respeitado.

Com isso, dar-nos-íamos por satisfeitos caso o excurso tenha alcançado o objetivo colimado, fazendo com que o leitor possa agora apreender a idéia abstrata e tão importante à compreensão do fenômeno jurídico, indiscutivelmente constituído por eficácia e por efeitos.

Porto Alegre, 28 de novembro de 2001.

Rua Quintino Bocaiúva, 694, conj. 502/503.

\footnotetext{
${ }^{21}$ Luis Recaséns Siches, in Experiencia Jurídica, Naturaleza De La Cosa y lógica 'Razonable', Fundo de Cultura Económica, Universidad Nacional Autónoma de México, 1971, p. 537.

${ }^{22}$ Idem ibidem, p.537.
} 


\section{BIBLIOGRAFIA}

DINAMARCO, Cândido Rangel: Fundamentos do Processo Civil, São Paulo, Malheiros, 2000, $3^{\underline{a}}$ ed., vol. I.

FALZEA, Angelo: Efficacia Giuridica, in Enciclopedia del Diritto, Itália, Giuffrè Editore, 1965, vol. XIV.

MIRANDA, PONTES: Tratado de Direito Privado, Rio de Janeiro, Borsoi, 1970, 3 ed., vol. 4 .

SICHES, Luis Recaséns: Experiencia Jurídica, Naturaleza de la Cosa y Lógica "Razonable", UNAM, 1971.

WARAT, Luis Alberto: ODireito E Sua Linguagem, Porto Alegre, Sergio Antonio Fabris, 1995, 2ª ed. 